\section{Uso de agrotóxicos e suicídios no Estado do Mato Grosso do Sul, Brasil}

\author{
Pesticide use and suicide in the State \\ of Mato Grosso do Sul, Brazil
}

Dario Xavier Pires 1

Eloísa Dutra Caldas ${ }^{2}$

Maria Celina Piazza Recena 1

\footnotetext{
1 Departamento de Química, Universidade Federal de Mato Grosso do Sul, Campo Grande, Brasil.

2 Faculdade de Ciências da Saúde, Universidade de Brasília, Brasília, Brasil.

Correspondência D. X. Pires

Departamento de Química, Universidade Federal de Mato Grosso do Sul. C. P. 549, Campo Grande, MS 79070-900, Brasil. msquim2001@yahoo.com.br
}

\begin{abstract}
Prevalence of suicide with pesticides in the State of Mato Grosso do Sul, Brazil, was evaluated based on data from the Integrated State Center for Toxicological Surveillance under the State Health Department and reported from January 1992 to December 2002. Population and crop production data were collected from the Brazilian Institute of Geography and Statistics, and suicide data were obtained from the State Health Department. During the period studied, 1,355 cases of pesticide poisoning were reported, including 506 suicide attempts, resulting in 139 deaths. The regions of Campo Grande and Dourados had the highest prevalence of suicide attempts, with Dourados having the most deaths. Dourados also had a high prevalence of suicide attempts overall, with an increasing trend in the previous 10 years. The results indicated that Dourados is a critical region in the State in terms of intentional ingestion of pesticides, showing the need for an epidemiological investigation to better evaluate and quantify these events among the rural population.
\end{abstract}

Pesticides; Suicide; Epidemiologic Surveillance

\section{Introdução}

O Brasil é o terceiro mercado e o oitavo maior consumidor de agrotóxicos por hectare no mundo, sendo os herbicidas e inseticidas responsáveis por $60,0 \%$ dos produtos comercializados no país 1. O Estado do Mato Grosso do Sul é o nono Estado agrícola no país, com 2.014.829ha em 2002 2, principalmente com culturas temporárias como o algodão, arroz, cana-de-açúcar, feijão, milho, soja e trigo, concentradas, principalmente, nas regiões norte-nordeste e sul do Estado. Pequenas propriedades (entre 30 e 280ha) e minifúndios (<30ha), representam $62,4 \%$ das propriedades rurais do Estado 3,4 . O uso indiscriminado de agrotóxicos no campo pode resultar na intoxicação dos trabalhadores rurais com diferentes graus de severidade, constituindo-se um grave problema de saúde pública, principalmente nos países em desenvolvimento 5,6,7. A Organização Mundial da Saúde 8 estima que ocorram anualmente no mundo cerca de 3 milhões de intoxicações agudas provocadas pela exposição aos agrotóxicos, com aproximadamente 220 mil mortes por ano.

O Serviço Integrado de Informação ToxicoFarmacológica do Ministério da Saúde 9, registrou em 2001, 5.384 casos de intoxicação provocados por agrotóxicos no país, correspondendo a $7,1 \%$ do total das intoxicações. Enquanto a taxa média de letalidade devido a todos os agentes causadores das intoxicações foi 
de $0,4 \%$, a mortalidade devido a agrotóxicos foi de $3,4 \%$. Do total de 8.697 casos de intoxicação atribuídos às tentativas de suicídio, $11,6 \%$ foram provenientes do uso de agrotóxicos. Estes números refletem apenas parcialmente a realidade do país, já que, segundo estimativas do Ministério da Saúde, para cada evento de intoxicação por agrotóxico notificado, existem outros cinqüenta não notificados 10.

Este estudo tem como objetivo principal conhecer o perfil das intoxicações, com ênfase nas tentativas de suicídio, pelo uso de agrotóxicos na população rural no Estado do Mato Grosso do Sul no período de 1992 a 2002. Por apontar áreas críticas e situações de risco, este trabalho pretende fornecer informações para que os serviços de epidemiologia e de vigilância sanitária tracem futuras políticas de prevenção a esses eventos no Estado.

\section{Metodologia}

As informações sobre áreas dos módulos dos estabelecimentos rurais e as populações urbanas e rurais foram obtidas do Censo Agropecuário do Instituto Brasileiro de Geografia e Estatística (IBGE) de 199611 e do Censo Populacional do IBGE 12 para os anos de 1980, 1991 e 2000. A produção agrícola das culturas temporárias de algodão, arroz, cana-de-açúcar, feijão, milho, soja e trigo nos municípios que compõem as 11 microrregiões geográficas do Estado foram obtidas da Produção Agrícola Municipal de 1992 a 2002 2. As microrregiões geográficas do Estado são: Baixo Pantanal, Aquidauana, Alto Taquari, Campo Grande, Cassilândia, Paranaíba, Três Lagoas. Nova Andradina, Bodoquena, Dourados e Iguatemi (Figura 1).

A demanda de inseticidas e herbicidas no ano de 2000, por cultura e pela população rural residente nas microrregiões, foi calculada comparando o volume desses agrotóxicos comercializados no país neste ano, divulgado pelo Sindicato Nacional da Indústria de Produtos para Defesa Agrícola, com a produção agrícola nacional das culturas temporárias selecionadas para este estudo, divulgada pelo IBGE 2, para igual período. Para cada cultura, a razão entre o volume de inseticidas ou herbicidas e a produção agrícola, em kg/t, foi multiplicada pela produção em cada microrregião, obtendo-se a demanda do agrotóxico por cultura em cada microrregião. A demanda de inseticidas ou herbicidas, dividida pela população rural
Figura 1

Microrregiões geográficas do Estado do Mato Grosso do Sul, Brasil.
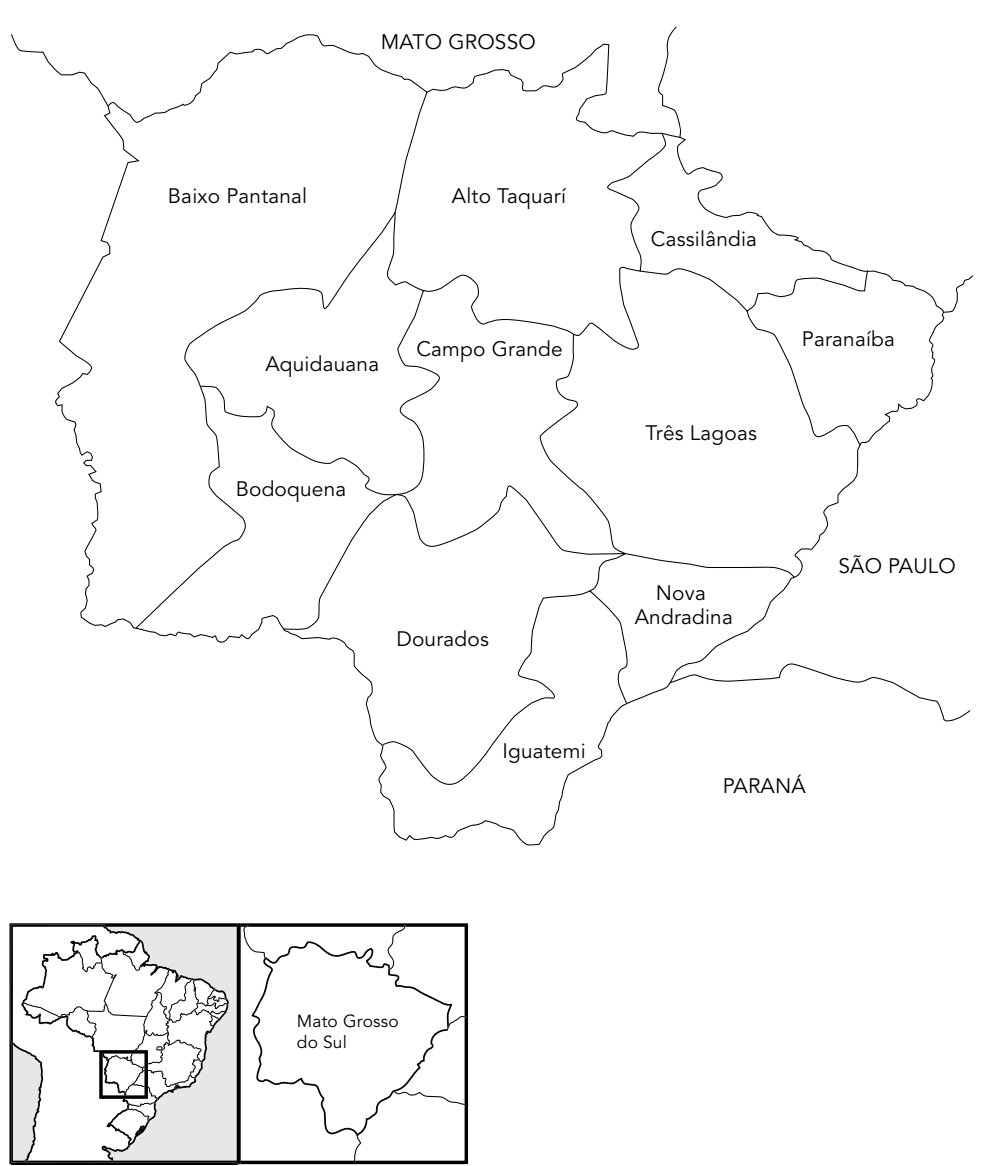

da microrregião, reflete a demanda de agrotóxicos por microrregião, em $\mathrm{kg} /$ habitantes, neste ano.

Dados de intoxicação por agrotóxicos de uso agrícola no período de janeiro de 1992 a dezembro de 2002 foram obtidos dos registros das notificações do Centro Integrado de Vigilância Toxicológica da Secretaria Estadual de Saúde do Estado do Mato Grosso do Sul (CIVITOX/ MS). As informações obtidas nas notificações incluem idade e sexo do intoxicado, município da ocorrência, data do evento, ocorrência de tentativas de suicídio, bem como a correspondente letalidade e os princípios ativos utilizados. Os dados coletados foram analisados usando-se o programa Epi Info 2000. 
Dados de tentativas de suicídio e de óbitos provocados pela ingestão de agrotóxicos de uso agrícola, obtidos junto ao CIVITOX/MS, foram normalizados para 100 mil habitantes, considerando a população da área rural. As populações rurais das microrregiões geográficas e do estado, no período de 1992 a 2002, foram estimadas valendo-se da análise de tendências de regressão polinomial (ordem $2, \mathrm{r}^{2}>0,85$ ), tomando como base os dados dos Censos Populacionais de 1980, 1991, 200012 e do Censo Agropecuário de 199611.

A Classificação Estatística Internacional de Doenças e Problemas Relacionados à Saúde 10ạ Revisão (CID-10) 13, enfoca as diferentes formas de suicídio ocorridas numa população, incluindo intoxicação por gases, afogamento, precipitação de lugares elevados, disparo de armas de fogo, enforcamento, uso de objeto cortante e ingestão de agrotóxicos ou outros produtos químicos. Dados de suicídios, segundo esta classificação, ocorridos nas microrregiões do estado, no período de 1992 a 2002, foram obtidas da Divisão de Epidemiologia da Secretaria de Estado de Saúde do Estado do Mato Grosso do Sul (dados não publicados). As prevalências de suicídios por estas causas, por 100 mil habitantes, foram calculadas considerando a população total.

As correlações entre as prevalências das tentativas de suicídio e das prevalências dos óbitos correspondentes com a cultura do algodão na microrregião de Dourados foram obtidas por meio das análises dos coeficientes de Pear- son (r), com índice de confiabilidade (IC) de 95\% e índice de significância $(p)<0,05$.

\section{Resultados}

Dados de demanda nacional de inseticidas e herbicidas e produção agrícola nacional mostram que o algodão é a cultura temporária que mais consome estes produtos no país. Em 2000, $78,0 \%$ de todo o inseticida comercializado e $29,2 \%$ de herbicida foram utilizados na cotonicultura. Feijão e soja consomem 15,6\% de inseticida, e trigo e soja $38,5 \%$ do herbicida consumido no país por ano 1 .

A Tabela 1 mostra a produção agrícola das culturas temporárias no Estado do Mato Grosso do Sul, por microrregião, no ano de 2000 , com ênfase na cultura do algodão, e a porcentagem de propriedades com $<50$ ha, consideradas como pequenas propriedades pelo Programa Nacional de Fortalecimento da Agricultura Familiar 4. As regiões de Alto Taquari, Dourados e Iguatemi representam, juntas, $72,8 \%$ da produção de lavouras temporárias no Estado e as regiões de Cassilândia e Dourados são as maiores produtoras de algodão. Enquanto 62,0\% das propriedades em Dourados têm $<50$ ha, a agricultura na microrregião de Cassilândia é caracterizada por propriedades de médio e grande porte (apenas 15,0\% com < 50ha).

As demandas calculadas de inseticidas e herbicidas no Estado, por microrregião (Tabela

Tabela 1

Produção das lavouras temporárias nas microrregiões geográficas do Estado do Mato Grosso do Sul, e estabelecimentos rurais com área menor que 50ha que cultivam estas lavouras. Estado do Mato Grosso do Sul, Brasil, 2000.

\begin{tabular}{|c|c|c|c|c|}
\hline \multirow[t]{2}{*}{ Microrregião } & \multicolumn{2}{|c|}{$\begin{array}{c}\text { Produção de lavouras } \\
\text { temporárias* }\end{array}$} & \multirow[t]{2}{*}{$\begin{array}{l}\text { Produção de } \\
\text { algodão (t) }\end{array}$} & \multirow{2}{*}{$\begin{array}{c}\text { Propriedade } \\
<50 h a \\
\%\end{array}$} \\
\hline & $\mathrm{t}$ & $\%$ & & \\
\hline Baixo Pantanal & 3.434 & 0,04 & 260,7 & 77 \\
\hline Aquidauana & 72.697 & 0,79 & $3.252,1$ & 84 \\
\hline Alto Taquari & 1.552 .530 & 16,90 & $5.850,1$ & 36 \\
\hline Campo Grande & 289.360 & 3,20 & $2.285,6$ & 39 \\
\hline Cassilândia & 758.899 & 8,20 & $40.465,8$ & 15 \\
\hline Paranaíba & 17.116 & 0,19 & 83,8 & 24 \\
\hline Três Lagoas & 861.005 & 9,40 & $1.317,8$ & 35 \\
\hline Nova Andradina & 417.092 & 4,50 & $4.690,4$ & 57 \\
\hline Bodoquena & 86.118 & 0,94 & 3477,6 & 66 \\
\hline Dourados & 3.916 .955 & 42,60 & $26.929,1$ & 62 \\
\hline Iguatemi & 1.226 .060 & 13,30 & $14.481,7$ & 79 \\
\hline Total no Estado & 9.202 .866 & 100,00 & $102.834,0$ & 60 \\
\hline
\end{tabular}

* Inclui algodão, arroz, cana-de-açúcar, feijão, milho, soja e trigo. 
População rural, consumo de princípios ativos $(\mathrm{kg})$ e demanda de princípios ativos por habitantes (kg/hab) das microrregiões geográficas do Estado do Mato Grosso do Sul, Brasil, 2000.

\begin{tabular}{|c|c|c|c|c|c|}
\hline \multirow[t]{3}{*}{ Microrregião } & \multirow{3}{*}{$\begin{array}{l}\text { População } \\
\text { rural (hab) }\end{array}$} & \multicolumn{4}{|c|}{ Princípios ativos } \\
\hline & & \multicolumn{2}{|c|}{ Inseticida } & \multicolumn{2}{|c|}{ Herbicida } \\
\hline & & $\begin{array}{c}\text { Consumo } \\
(\mathrm{kg})\end{array}$ & $\begin{array}{c}\text { Demanda } \\
\text { (kg/hab) }\end{array}$ & $\begin{array}{c}\text { Consumo } \\
(\mathrm{kg})\end{array}$ & $\begin{array}{c}\text { Demanda } \\
\text { (kg/hab) }\end{array}$ \\
\hline Baixo Pantanal & 19.504 & 378 & 0,02 & 1.816 & 0,09 \\
\hline Aquidauana & 28.981 & 2.133 & 0,07 & 24.732 & 0,85 \\
\hline Alto Taquari & 20.591 & 115.038 & 5,60 & 386.294 & 18,80 \\
\hline Campo Grande & 27.713 & 43.616 & 1,60 & 440.721 & 15,90 \\
\hline Cassilândia & 9.650 & 255.104 & 26,40 & 664.658 & 68,90 \\
\hline Paranaíba & 14.394 & 737 & 0,05 & 10.101 & 0,70 \\
\hline Três Lagoas & 24.393 & 18.946 & 0,78 & 340.792 & 14,00 \\
\hline Nova Andradina & 19.121 & 10.830 & 0,57 & 156.853 & 8,20 \\
\hline Bodoquena & 23.714 & 10.820 & 0,46 & 62.235 & 2,60 \\
\hline Dourados & 69.455 & 290.207 & 4,20 & 2.214 .527 & 36,00 \\
\hline Iguatemi & 66.000 & 40.335 & 0,61 & 456.881 & 6,90 \\
\hline Total no Estado & 696.144 & 788.144 & 1,13 & 4.759 .510 & 6,84 \\
\hline
\end{tabular}

2), permitiram determinar, além da demanda regional desses produtos, a relação entre essas demandas e as populações rurais residentes nessas regiões. Dourados e Iguatemi possuem as maiores populações rurais do Estado, enquanto Alto Taquari, Cassilândia e Dourados apresentam as maiores demandas de inseticidas e herbicidas por habitante.

O CIVITOX/MS registrou entre 1992 e 2002, 1.355 notificações de intoxicação provocadas pelo manuseio e pelo uso de agrotóxicos utilizados na agricultura, sendo que 501 dessas notificações foram provenientes da ingestão voluntária desses produtos (tentativa de suicídio), com 139 óbitos (Tabela 3). Campo Grande e Dourados apresentaram os maiores números de notificações e de prevalência de tentativa de suicídios (por 100 mil habitantes, considerados da área rural), sendo que Dourados, em especial, apresentou também a maior prevalência de óbitos. Apesar do alto número de tentativas de suicídio encontrado em Campo Grande no período (135 notificações), esta região é a sétima região agrícola do Estado (Tabela 1), apresentando baixa produção de algodão e demanda de aplicação de agrotóxicos (Tabela 2).

Enquanto no Brasil a média de óbitos por 100 mil habitantes provocados pelas diferentes formas de suicídio, listadas no CID-10, foi de 3,9 \pm 1,5 no período de 1977 a 1997 14, Mato Grosso do Sul apresentou uma média de 6,5 \pm 0,9 óbitos no período de 1992 a 2002 (Secretaria de Estado de Saúde/Ministério da Saúde,
Tabela 3

Notificações das tentativas de suicídio e de óbitos provocadas pela ingestão voluntária de agrotóxicos no Mato Grosso do Sul, Brasil, no período de 1992 a 2002.

\begin{tabular}{lccc}
\hline Microrregião & $\begin{array}{c}\text { Tentativas de } \\
\text { suicídio/óbitos }\end{array}$ & $\begin{array}{c}\text { Prevalência* } \\
\text { (média de tentativas } \\
\text { de suicídio) }\end{array}$ & $\begin{array}{c}\text { Prevalência* } \\
\text { (média de óbitos) }\end{array}$ \\
\hline Baixo Pantanal & $3 / 1$ & 1,5 & 0,5 \\
Aquidauana & $10 / 2$ & 3,0 & 0,3 \\
Alto Taquari & $14 / 6$ & 6,2 & 2,9 \\
Campo Grande & $135 / 9$ & 40,1 & 2,7 \\
Cassilândia & $1 / 0$ & 7,6 & 0,0 \\
Paranaíba & $10 / 4$ & 6,3 & 2,9 \\
Três Lagoas & $22 / 5$ & 8,0 & 1,7 \\
Nova Andradina & $17 / 7$ & 8,0 & 3,6 \\
Bodoquena & $25 / 11$ & 9,2 & 4,5 \\
Dourados & $203 / 63$ & 25,6 & 8,5 \\
lguatemi & $61 / 31$ & 8,5 & 4,4 \\
Total no Estado & $501 / 139$ & $11,3(11,4)$ & $2,9(2,4)$ \\
(desvio padrão) & & & \\
\hline
\end{tabular}

* Por 100 mil habitantes, considerados da área rural.

dados não publicados). As microrregiões de Dourados, Cassilândia, Iguatemi e Paranaíba apresentaram prevalência média de suicídios no período de 1992 a 2002 maiores que a prevalência média do Estado do Mato Grosso do Sul $(9,9 \pm 3,0 ; 8,6 \pm 3,3 ; 8,0 \pm 1,8$ e $7,7 \pm 3,3$, respectivamente). A Figura 2 mostra os padrões de tendência de variação da prevalência de sui- 
Regressão polinomial (ordem 2, r2 > 0,90) da prevalência de suicídios classificados pelo CID-10 13, por 100 mil habitantes da população total no período de 1992 a 2002, no Estado do Mato Grosso do Sul (1) e nas microrregiões de Dourados (2), Paranaíba (3), Cassilândia (4) e Iguatemi (5).

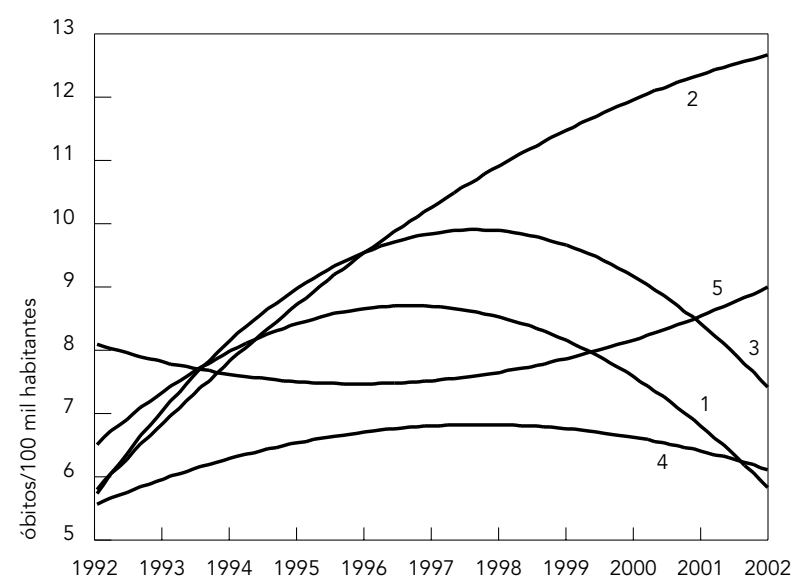

cídios no Estado e nessas microrregiões. Dourados se destaca por apresentar um padrão de tendência crescente durante todo o período, diferentemente de Cassilândia, Paranaíba e do Estado, onde houve uma tendência de queda a partir de 1997. Em Iguatemi, a prevalência aumentou nos últimos anos, porém em níveis inferiores aos de Dourados.

A Figura 3 apresenta para a microrregião de Dourados, no período de 1992 a 2002, os dados de prevalência das tentativas de suicídio e de óbitos por 100 mil habitantes, considerados da área rural, provocados pela ingestão voluntária de agrotóxicos, e a produção de algodão. Como os registros do CIVITOX/MS não apresentaram informações referentes aos cinco últimos meses do ano de 1996, as correlações para a prevalência das tentativas de suicídio foram calculadas considerando ou não este ano. Foi verificada correlação estatisticamente significativa entre a produção de algodão e a prevalência das tentativas de suicídio na microrregião $(\mathrm{r}=$ 0,61 e 0,83 , com e sem os dados de 1996, respectivamente), porém a correlação entre a produção de algodão e a prevalência dos óbitos nesta região foi baixa $(r=0,24)$.

\section{Discussão}

Vários estudos demonstram que os inseticidas, principalmente organofosforados e carbamatos, são os principais causadores das intoxicações humanas ocorridas no campo 6,15,16,17,18. Alguns estudos relacionam a exposição aos inseticidas com sintomas de depressão. Rehner et al. 19, investigando um desastre ecológico com o organofosforado parationa metílica ocorrido no Mississipi (Estados Unidos), observaram que independente dos níveis do agrotóxico encontrado na água consumida, mais da metade das pessoas expostas apresentaram sintomas de depressão. Stallones \& Beseler 20 encontraram uma relação direta entre a ocorrência de sintomas de intoxicação com organofosforados em agricultores do Estado do Colorado e sintomas de depressão. Num estudo semelhante, Scarth et al. 21 encontraram riscos maiores de desenvolvimento de depressão em trabalhadores do Estado de Iowa comparados aos do Colorado. Um estudo realizado nos municípios de Antônio Prado e Ypê no Estado do Rio Grande do Sul, Brasil 22, indicou que a ocorrência de intoxicações agudas provocadas pela exposição aos agrotóxicos está fortemente associada à prevalência de transtornos psiquiátricos menores, sendo a depressão e a ansiedade os diagnósticos mais freqüentes.

Sintomas de depressão são reconhecidos como um fator prevalente nas tentativas de suicídios. Um estudo conduzido na Espanha mostrou que a taxa de suicídios em áreas agrícolas é significativamente maior que em outras regiões geográficas com características sócio-econômicas e demográficas similares 23 . No Canadá foi observado um significativo aumento do risco de suicídios em grupos de agricultores que aplicavam inseticidas e herbicidas comparados com grupos não expostos 24 , e nos Estados Unidos, van Wijngaarden 25 observou que o maior risco de suicídios pela exposição a agrotóxicos ocorria em indivíduos entre 35 e 49 anos.

No Brasil, a produção de algodão demanda quase $80,0 \%$ de todo o inseticida comercializado no país 1 . Embora a cultura do algodão não possa ser considerada determinante para a ocorrência de suicídios numa região, a correlação encontrada neste estudo (Figura 3) pode significar um fator de risco, no que diz respeito à exposição humana aos inseticidas, associado às características do manejo desta cultura, na região de Dourados. A microrregião de Dourados, segunda produtora de algodão do Estado, é caracterizada principalmente por pequenas propriedades, onde predominam a pulverização de agrotóxicos por tratores e aplicadores 
Produção de algodão em toneladas (t) e registro das tentativas de suicídio e de óbitos, por 100 mil habitantes,

considerados da área rural, microrregião de Dourados, 1992 a 2002.

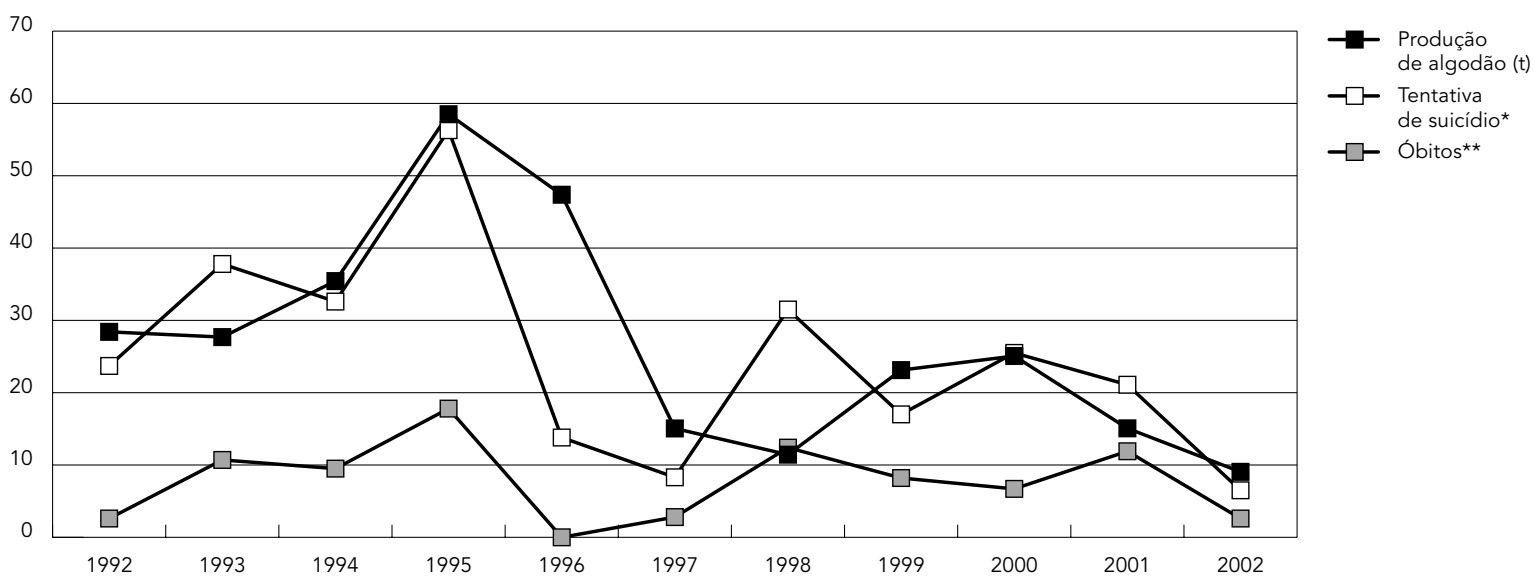

Correlação entre a produção de algodão/tentativa de suicídio, incluindo dados de 1996: $r=0,61$,

IC95\% = 0,01-0,88, $\mathrm{p}=0,0484$; correlação entre a produção de algodão/tentativa de suicídio, sem dados

de 1996: $r=0,83$, IC $95 \%=0,42-0,96, p=0,0030$; produção/óbitos: $r=0,24, I C 95 \%=-0,42-0,73, p=0,4775$.

costais 26. Estas formas de aplicação possibilitam maior contato do homem com os agrotóxicos e envolvem um maior número de trabalhadores. Adicionalmente, pequenos agricultores têm, normalmente, menos acesso à orientação técnica e à informação quanto a esses produtos, o que aumenta o risco de uso indevido. O maior potencial de exposição a agrotóxicos dos trabalhadores rurais, nas pequenas propriedades da microrregião de Dourados, pode explicar o alto número de notificações de tentativa de suicídios e óbitos devido ao uso desses produtos.

Cassilândia é a principal região algodoeira do Estado com $71,0 \%$ da produção atualmente. A cotonicultura em Cassilândia se desenvolveu a partir dos meados da década de 1990, como um contraponto ao decréscimo dessa cultura na microrregião de Dourados que, historicamente, sempre foi a sua principal produtora. Cassilândia, que apresenta a maior demanda de inseticidas com relação à sua população rural (Tabela 2), possui, principalmente, médias e grandes propriedades, onde predominam a aplicação aérea de agrotóxicos 27. É provável que o pouco contato humano com os agrotóxicos, característico desta tecnologia de aplicação, tenha relação direta com o baixo número de notificações de intoxicação e de tentativa de suicídio provocados pela exposição a agrotóxi- cos observado neste estudo na região (oito notificações), somente menor que a microrregião do Baixo Pantanal.

A microrregião de Campo Grande apresentou a maior prevalência de tentativa de suicídio pela ingestão de agrotóxico e o segundo maior número deste tipo de ocorrência no Estado. Campo Grande é apenas a sétima região agrícola do Estado e apresenta baixa demanda de aplicação de agrotóxicos quando comparada a Dourados, Cassilândia e Alto Taquari. Na microrregião de Campo Grande está situado o Município de Campo Grande, a capital, que dispõe da melhor infra-estrutura do Estado na área de atendimento à saúde. A eficiente assistência à saúde existente, pode estar relacionada a baixos índices de subnotificação e talvez seja responsável pela baixa prevalência de óbitos em relação às tentativas de suicídio, comparada com outras regiões do Estado.

No único levantamento publicado até o momento sobre intoxicações por agrotóxicos no Mato Grosso do Sul, Gonzaga \& Santos 26 avaliaram as condições de trabalho dos cotonicultores dos municípios de Fátima do Sul e Vicentina (microrregião geográfica de Dourados) e Glória de Dourados (microrregião geográfica de Iguatemi). Esse estudo indicou que $84,0 \%$ dos 148 trabalhadores pesquisados apresentavam sintomas de intoxicação. Cerca de 60,0\% 
desses trabalhadores trabalhavam mais que seis horas/dia na lavoura e $18,0 \%$ não empregavam qualquer medida de proteção durante o manuseio dos agrotóxicos, configurando uma prática agrícola com níveis baixos de tecnologia e com assistência técnica deficiente, desenvolvida em moldes familiares.

O presente estudo indicou ser Dourados uma microrregião crítica do Estado do Mato Grosso do Sul com relação às ocorrências de tentativa de suicídio, seja por ingestão de agrotóxicos pela população rural ou por causas diversas. É provável que esta alta prevalência esteja relacionada com a exposição dos trabalhadores rurais aos agrotóxicos, o que indica a necessidade de se iniciar um programa de vigilância epidemiológica na região, até agora inexistente, para melhor avaliar, comparar e quantificar estes eventos.

\section{Resumo}

As prevalências das tentativas de suicídio provocadas pela exposição a agrotóxicos de uso agrícola no Estado do Mato Grosso do Sul, Brasil, ocorridas entre janeiro 1992 a dezembro 2002, foram avaliadas baseadas nos registros das notificações de intoxicação do Centro Integrado de Vigilância Toxicológica da Secretaria de Saúde do Estado. Dados populacionais e de produção agrícola foram obtidos do Instituto Brasileiro de Geografia e Estatística, e dados de suicídio por causas diversas da Secretaria de Estado de Saúde. Foram registradas 1.355 notificações de intoxicação, sendo 506 tentativas de suicídio que levaram a 139 óbitos. As microrregiões de Campo Grande e Dourados apresentam as maiores prevalências de tentativas de suicídio. Alta prevalência de suicídios por causas diversas também foi observada em Dourados, com uma tendência de crescimento nos últimos dez anos. Os resultados deste estudo indicaram a microrregião de Dourados como uma das mais críticas do Estado do Mato Grosso do Sul com relação à ingestão voluntária de agrotóxicos, demonstrando a necessidade de um programa de vigilância epidemiológica para melhor investigar estes eventos na população rural da região.

Praguicidas; Suicídio; Vigilância Epidemiológica

\section{Colaboradores}

D. X. Pires e E. D. Caldas elaboraram o artigo. M. C. P. Recena participou da coleta e avaliação dos dados do Centro Integrado de Vigilância Toxicológica da Secretaria Estadual de Saúde do Estado de Mato Grosso do Sul (CIVTOX/MS). 


\section{Referências}

1. Fairbanks M. Defensivos agrícolas ampliam o mercado. Revista Química e Derivados 2001; 396: 398-403.

2. Instituto Brasileiro de Geografia e Estatística. Produção Agrícola Municipal, 1992-2002. http://www. sidra.ibge.gov.br/bda (acessado em 14/Set/2004).

3. Instituto Nacional de Colonização e Reforma Agrária. Estatísticas cadastrais municipais - recadastramento 1992 - volume I. Tabela 3 - Distribuição das áreas de preservação do meio ambiente. http://www.incra.gov.br/_htm/serveinf/_htm/es tat/1992/tab3.htm (acessado em 14/Set/2004).

4. Banco Nacional de Desenvolvimento Econômico e Social. Programa nacional de fortalecimento da agricultura familiar. http://www.bndes.gov.br/ programas/agropecuarios/pronaf.asp (acessado em 14/Set/2004).

5. Meredith TJ. Epidemiology of poisoning. Pharmacol Ther 1993; 59:252-6.

6. Senanayake N, Peires H. Mortality due to poisoning in a developing agricultural country: trends over 20 years. Hum Exp Toxicol 1995; 14:808-11.

7. Hoek W, Konradsen F, Athukorala K, Wanigadewa T. Pesticide poisoning: a major health problem in Sri Lanka. Soc Sci Med 1998; 46:4-7.

8. World Health Organization. Public health impact of pesticides used in agriculture. Geneva: World Health Organization; 1990.

9. Sistema Nacional de Informações Tóxico-Farmacológicas. Casos registrados de intoxicação humana por agente tóxico e circunstância. http:// www.cict.fiocruz.br/intoxicacoeshumanas/ 2001/brasil2001.htm (acessado em 14/Set/2004).

10. Peres F, Rozemberg B, Alves SR, Moreira JC, Oliveira-Silva JJ. Comunicação relacionada ao uso de agrotóxicos em região agrícola do Estado do Rio de Janeiro. Rev Saúde Pública 2001; 35:564-70.

11. Instituto Brasileiro de Geografia e Estatística. Banco de dados agregados. Censo agropecuário 1996. http://www.sidra.ibge.gov.br/bda/agric/ default.asp?z=t\&o=11 (acessado em 14/Set/2004).

12. Instituto Brasileiro de Geografia e Estatística. Censos demográficos 1980, 1991, 2000. http://www. sidra.ibge.gov.br/bda/tabela/listabl.asp?c $=202 \& z$ $=\mathrm{t} \& \mathrm{O}=4$ (acessado em 14/Set $/ 2004)$.

13. Ministério da Saúde. Classificação estatística internacional de doenças e problemas relacionados à saúde 10ạ revisão. http:// www.datasus.gov.br/ cid10/cid10.htm (acessado em 14/Set/2004).

14. Jorge MHPM, Gawryszewski VP, Latorre MRDO. I - análise dos dados de mortalidade. Rev Saúde Pública 1997; 31 Suppl:5-25.

15. Saadeh AM, Alaly MK, Farsakh NA, Ghani MA. Clinical and socio demographic future of acute carbamate and organophosphate poisoning: a study of adult patients in North Jordan. J Toxicol Clin Toxicol 1996; 34:45-51.
16. Soth T, Hosokawa M. Organophosphate and their impacts on the global environment. Neurotoxicology 2000; 21:1-4.

17. Campanhola C, Bettiol W. Panorama sobre o uso de agrotóxicos no Brasil. In: Programa de defesa ambiental rural. 1a Ed. v. 1. Brasília: Fórum Nacional de Secretários de Agricultura; 2002. p. 7-26.

18. Lidwien AM, Smith BN, van Wendel DJ, Dick H Roshin JP, van der Hoek W. Neurological symptoms among Sri Lanka farmers occupationally exposed to acetyl cholinesterase-inhibiting insecticides. Am J Ind Med 2003; 44:254-64.

19. Rehner TA, Kolbo JR, Trump R, Smith C, Reid D. Depression among victims of south Mississippi's methyl parathion disaster. Health Soc Work 2000; 25:33-40.

20. Stallones L, Beseler C. Pesticide poisoning and depressive symptoms among farm residents. Ann Epidemiol 2002; 12:389-94.

21. Scarth RD, Stalones L, Zwerling C. The incidence of depressive symptoms and risk factors among Iowa and Colorado farmers. Am J Ind Med 2000; 37:382-9.

22. Faria NMX, Facchini LA, Fassa ACG, Tomasi E. Processo de produção rural e saúde na serra gaúcha: um estudo descritivo. Cad Saúde Pública 2000; $16: 115-28$.

23. Parron T, Hernandez AF, Villanueva E. Increased risk of suicide with exposure to pesticides in an intensive agricultural area. A 12-year retrospective study. Forensic Sci Int 1966; 79:53-63.

24. Pickett W, King WD, Lees RE, Bienefeld M, Morrison HI, Brison RJ. Suicide mortality and pesticide use among Canadian farmers. Am J Ind Med 1998; 34:364-72.

25. van Wijngaarden E. An exploratory investigation of suicide and occupational exposure. J Occup Environ Med 2003; 45:96-101.

26. Gonzaga MC, Santos SO. Avaliação das condições de trabalho inerentes ao uso de agrotóxicos nos municípios de Fátima do Sul, Glória de Dourados e Vicentina - Mato Grosso do Sul. Rev Bras Saúde Ocup 1991; 72:213-5.

27. Melo GA, Richett IA. Cadeia produtiva do algodão em Mato Grosso do Sul, Eficiência econômica e produtividade. Centro de Pesquisa Agropecuária do Oeste 2003. http:/ /www.cpao.embrapa.br/pu blicacoes $/$ ficha.php?tipo $=$ DOC \& num $=54 \&$ ano $=2$ 003 (acessado em 14/Set/2004).

Recebido em 20/Mai/2004

Versão final reapresentada em 30/Set/2004

Aprovado em 13/Out/2004 